\title{
Atrial septal defect type II and upper limb malformation in 40-year-old male as a manifestation of Holt-Oram syndrome
}

\author{
Ewa Szymczyk, Paulina Wejner-Mik, Piotr Lipiec, \\ Błażej Michalski, Jarosław D. Kasprzak \\ Department of Cardiology, Medical University of Lodz, Poland
}

The present study is the case of a 40 -year-old Caucasian male with bilateral, symmetric malformation of the upper limbs; absence of I metacarpals and thumbs (Fig. 1D, E). He was admitted to the Department of Cardiology because of impaired exercise tolerance (New York Heart Association [NYHA] II/III) and recurrent palpitations. His mother died when he was an infant at the age of 36 years, and two of his brothers died at the age of 3 and 15 years because of untreated congenital heart disease - none of them presented with skeletal abnormalities.

On electrocardiogram sinus rhythm was $70 \mathrm{bpm}$, first-degree atrioventricular block and incomplete right bundle branch block were found. Transthoracic and transesophageal echocardiography revealed normal left ventricular function and right ventricular overload due to large, an unusually elongated (elliptic, $27 \times 13 \mathrm{~mm}$ in size) type II atrial septal defect with hemodynamically significant left-to-right shunt (TAPSE $20 \mathrm{~mm}$, S' RV $13 \mathrm{~cm} / \mathrm{s}$, RVIT $52 \mathrm{~mm}$, RAA $24 \mathrm{~cm}^{2}$, Fig. 1A, B). Based on four-dimensional echocardiographic area sizing, an atrial septal defect nitinol occluder (Memopart $26 \mathrm{~mm}$, Lepu Medical) was implanted percutaneously via femoral vein (Fig. 1C) with complete atrial septal defect closure. Control echocardiography after 3 and 6 months showed a good result of occluder implantation with significant clinical improvement (NYHA I).

This case report is an example of Holt-Oram syndrome (heart-hand syndrome) which is an autosomal dominant disorder characterized by upper limb malformations in association with congenital heart lesions and increased risk for cardiac conduction abnormalities. Life expectancy for Holt-Oram syndrome varies among affected individuals and predominantly depends on the severity of the congenital heart defect.

Conflict of interest: None declared

Address for correspondence: Ewa Szymczyk, MD, PhD, Department of Cardiology, Bieganski Hospital, Medical University of Lodz, ul. Kniaziewicza 1/5, 91-347 Łódź, Poland, tel/fax: + 484225160 15, e-mail: eszymczyk@ptkardio.pl 


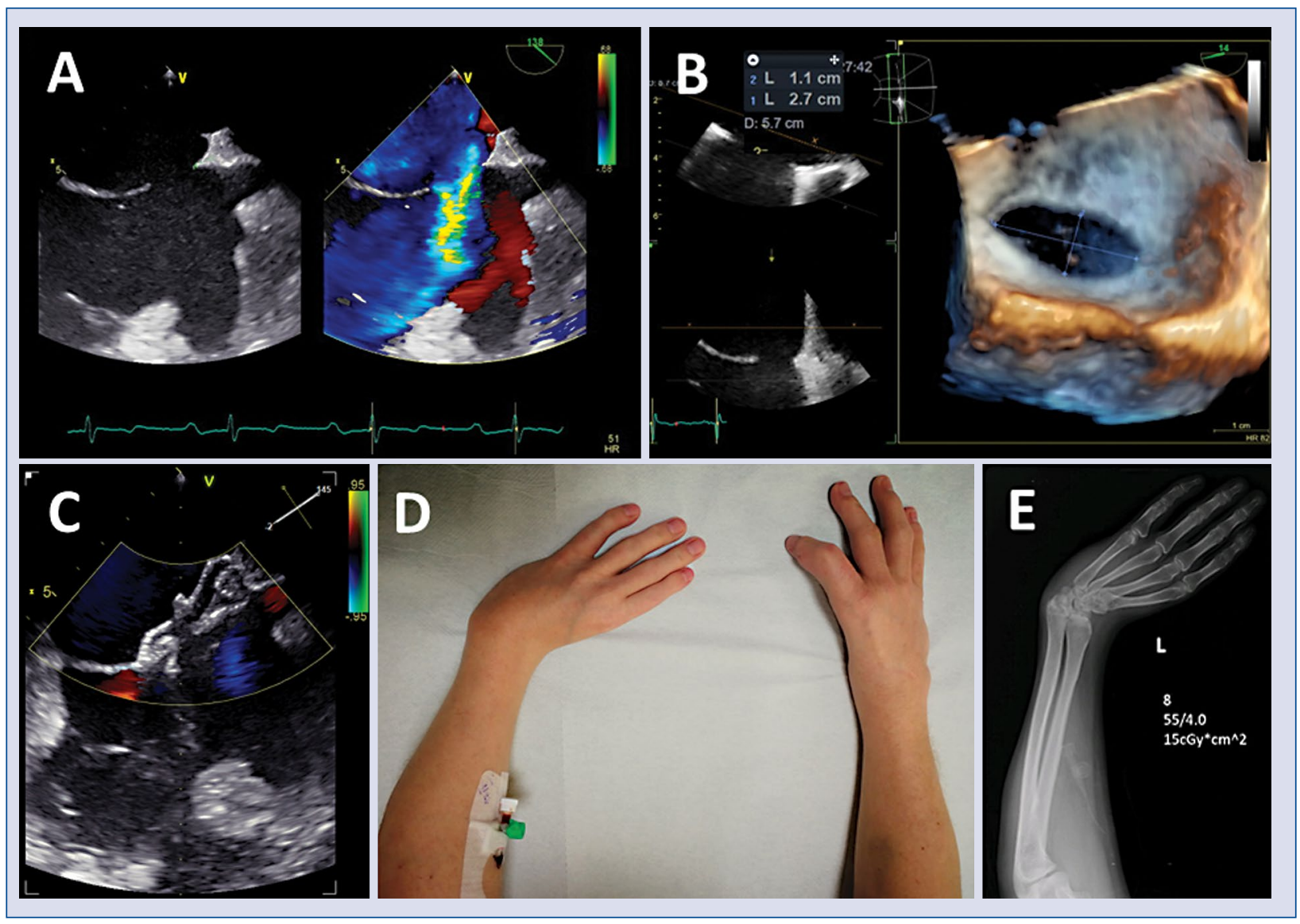

Figure 1. A. Two-dimensional transesophageal echocardiography with color Doppler — type II atrial septal defect with hemodynamically significant left-to-right shunt; B. Three-dimensional transesophageal echocardiography - elongated (elliptic, $27 \times 13 \mathrm{~mm}$ in size) type II atrial septal defect; C. Two-dimensional transesophageal echocardiography with color Doppler — good result of Memopart $26 \mathrm{~mm}$ occluder implantation; D, E. Malformation of upper limbs (real photo and X-ray) - absence of I metacarpals and thumbs. 